\title{
Gender Difference on Perceived Stress among Adults with Diabetes in Karachi-Pakistan
}

\author{
Umara Rauf \\ Uzma Ali \\ \& \\ Mahjabeen Tariq \\ Institute of Clinical Psychology \\ University of Karachi
}

\begin{abstract}
The aim of the present study was to explore the difference between perceived stress among male and female adults with diabetes in Karachi. On the basis of detailed literature review, it was hypothesized that there will be a significant difference on the scores of perceived stress among males and female diabetic adults. A purposive sample of (96 adults) 48 males and 48 females (diabetic patients) age range of 25 to 75 (mean=41.2 and $\mathrm{SD}=12.3$ ) who belong to different socioeconomic status were selected from different hospitals of Karachi. After taking individual consent demographic information was taken through self-developed demographic form. Perceived Stress Scale (PSS-Urdu Version) was used to measure the meaning of an event and adequacy of coping resources. After scoring, to evaluate the results t-test was applied for statistical analysis. And the findings revealed significant gender difference on the variable of perceived stress $(\mathrm{p}<.05)$ and female diabetics score higher than male diabetics. Findings from the study were helpful for physicians, health care practitioners and clinical psychologists.
\end{abstract}

Keywords: Male, Female, Adults, Diabetes, Perceived Stress

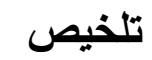

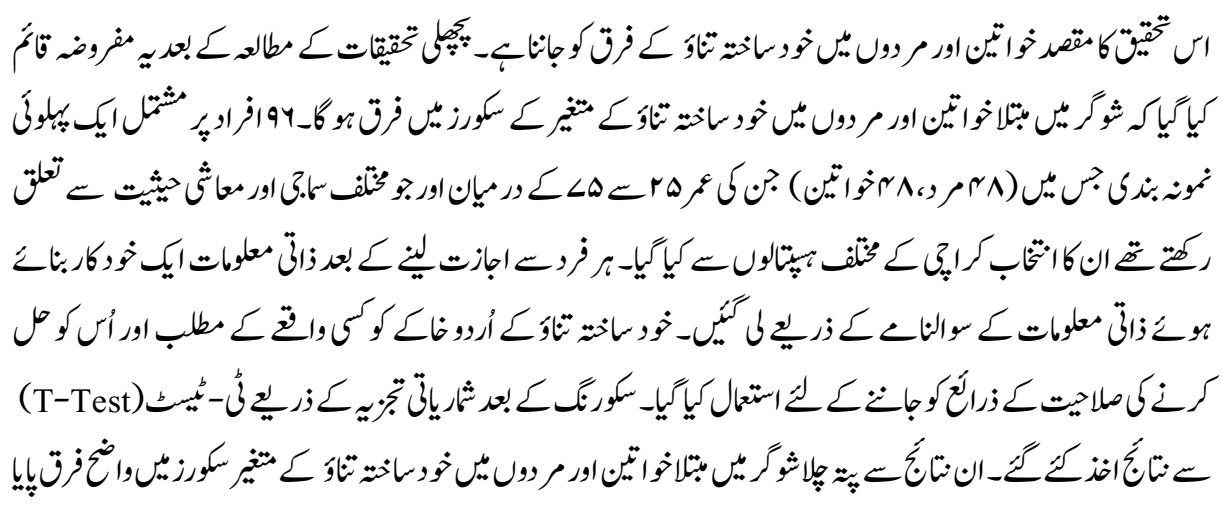




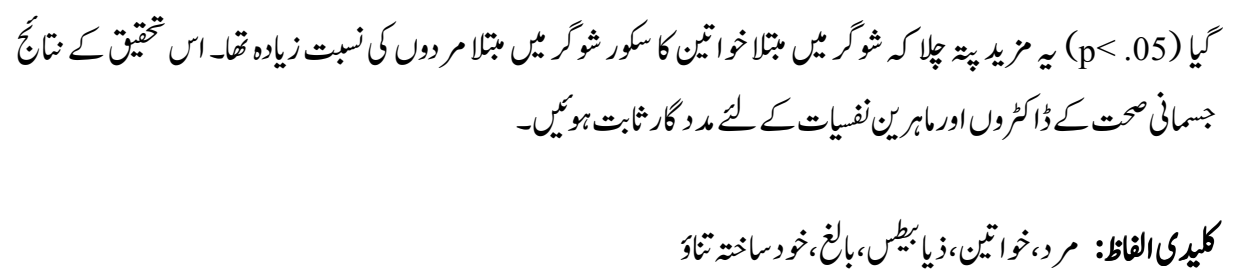

\section{Introduction}

Diabetes occurs when body is not capable to use insulin properly and working of pancreas is not sufficient to produce enough insulin (World Health Organization, 2010). It has three major types exposed by Drum and Zierenberg (2005) as type I and type II according to national diabetes data group.

Type I diabetes usually occurs early in life or in young adulthood that can only be treated through direct insulin injections (International Diabetes Federation, 2010) while type II diabetes can occur at any stage of life and can be managed through medicines so injections are not majorly choice of treatment for it but can only be used in severe conditions (Vinicor, 2004). It is more frequently reported type in current era (WHO \& International Diabetes Federation, 2010) with prevalence ratio of $22.04 \%$ and $17.15 \%$ in urban and rural areas of Pakistan (Shera, Jawad, \& Maqsood, 2007) and its ratio in Palestinian females and males has exceed to $9.6 \%$ and $10.0 \%$ respectively (Husseini, Abdul-Rahim, Awartani, Jervell, \& Bjertness, 2000). And the third type according to International Diabetes Federation (2006) is gestational diabetes that occurs when insulin receptors do not function properly during pregnancy.

Diabetic patients face hard physical trials of exhaustion, low energy, and faintness (Samuel-Hodge et al., 2000) and other comorbid medical complications of brain damage, diseases of the heart (American Diabetic Association, 2007) renal and eye (Riaz, 2009). Ratio of being diagnosed as diabetes is high in males with lower rate of BMI than females (Public Health Agency of Canada, 2011; Logue et al., 2011). In most of the countries males have more high mortality risk by this disease than females but ratio of poorer health is high among females than males (Malmusi, Artazcoz, Benach, \& Borrell, 2012) and in some other countries risk of mortality and hospitalization is high in females than males (Barnett, Ogston, McMurdo, Morris, \& Evans, 2010).

Psychological complications emerge when a person is diagnosed with diabetes, it is not only stressful for that person but also distressing to the care giver whom loved one is being declared as having diabetes (Vroomen-Durning, 2009). Initially he/she rejects 
and disowns this disease (Gazmararian, Ziemer, \& Barnes, 2009; Adriaanse et al., 2008; Delahanty et al., 2007; Drum \& Zierenberg, 2005; Goldstein \& Muller-Wieland, 2003). Further, patients with diabetes become tensed and start having apprehensions about their disease (Alberti, 2002; Cherrington, Ayala, Sleath, \& Corbie-Smith, 2006; Manderson \& Kokanovic, 2009; Penckofer, Ferrans, Velsor Friedrich, \& Savoy, 2007), gradually loses patience and tolerance and become fearful (Cherrington, Ayala, Sleath, \& Corbie-Smith, 2006; Drum \& Zierenberg, 2005; Goldstein \& Muller-Wieland, 2003; Penckofer Ferrans, Velsor, Friedrich, \& Savoy, 2007), frustrated (Gazmararian et al., 2009; Penckofer Ferrans, Velsor, Friedrich, \& Savoy, 2007) depress (Drum \& Zierenberg, 2005; Gazmararian, Ziemer, \& Barnes, 2009; Goldstein \& Muller-Wieland, 2003; Harris, 2007; Samuel-Hodge et al., 2000; Rauf \& Ali, in press) and remain in constant stress (Cosgrove, Sargeant, Caleyachetty, \& Griffin, 2012) and when patients with diabetes are unable to manage this disease they are overwhelmed by guilt (Cherrington, Ayala, Sleath, \& Corbie-Smith, 2006; Drum \& Zierenberg, 2005; Goldstein \& Muller-Wieland, 2003).

Stress is a vital risk factor of type II diabetes and more prevalent in diabetic patients with high blood pressure and lack of physical activity (Bener, Al-Hamaq \& Dafeeah, 2011; Jiang et al., 2007). In a domestic research perceived stress is found more in patients with diabetes (Rauf, 2012) unfortunately females are at greater risk by this psychological pressure and constant tension than males (Heraclides, Chandola, Witte, \& Brunner, 2012). And similar results were found in a previous research by Kaur, Tee, Ariaratnam, Krishnapillai, and China (2013) that stress is associated with females with other comorbid conditions like high blood pressure, duration of their disease and the way they are managing their metabolic disease.

However, other psychosocial factors are also evident like education level, being housewives, economic condition of family, support from social circle, resources to cope with this disease and the coping style itself are the contributing significant particles of enhancing stress in females (Sacerdote, Ricceri, Rolandsson, Baldi, Chirlaque \& Feskens, 2012; Smith et al., 2010; Chida \& Hamer, 2008) upsetting diabetes, in initiation and in its aggravation (Luthra, 2010; Pouwer, Kupper \& Adriaanse, 2010). Low level of education was a great stressful factor for females for being late assessed of having diabetes and for coping this disease (Madonna, Roche, Peizhong, 2014).

Different coping strategies have been used by diabetic patients to manage with stress of this disease. According to Lazarus and Folkman (1984) when a person deals with internal and external demands by constantly changing communicative and intellectual efforts that 
consequently produce excess of resources and opportunities for that person is called coping. People with diabetes according to the situation and their internal demands used spiritual coping (Anderson et al, 2000; Chin, Polonsky, Thomas, \& Nerney, 2000; Jones et al., 2008; Polzer \& Miles, 2005, 2007; Samuel-Hodge et al., 2000), different strategies of problems focused and emotional focused coping (Collins, Bradley, Sullivan, \& Perry, 2009; Samuel-Hodge et al; Tuncay, Musabak, Gok, \& Kutlu, 2008; Willoughby, Kee, Demi \& Parker, 2000) and when they hesitate to discuss about their disease in front of others feeling it less worthy to disclose they use avoidant coping (Coelho, Amorim \& Prata, 2003).

The main base of this research is to explore how perceived stress influenced lives of male and female adults with diabetes differently and what challenges they both have to face by carrying this chronic malady. And what perception and attitude they have about this disease would absolutely open new doors for mental and medical health practitioners to help such people in handling this disease by alleviating psychological strain. The current study is also fruitful for the general population as well as promoting better coping of stress and adapting healthy life style. On the basis of previous literature following hypotheses are generated:

- There will be a significant difference on the scores of perceived stress among males and female diabetic adults.

- There would be significant difference between the means scores of male and female persons with diabetes on the variable of perceived stress.

\section{Method}

\section{Participants}

A total sample of 96 adults with diabetes (male, $48 \&$ female, 48) diagnosed by the physicians were taken through purposive sampling from different hospitals of Karachi, Pakistan. Their age range was between 25 to 75 (mean age $=41.2, \mathrm{SD}=12.3$ ) and they belong to different socioeconomic status i.e.; lower, middle and high socioeconomic status. Their level of education was at least $5^{\text {th }}$ grade and their job status was categorized from retired/housewives to own business.

\section{Inclusion and Exclusion Criteria for Both Male and Female Diabetic Sample}

Following criteria was set for the diabetic participants for inclusion and exclusion in this study:

a) Who were within the age range of 25 to 75 years. 
b) Who had an at least primary level $\left(5^{\text {th }}\right.$ grade $)$ of education were selected.

c) Only Type II diabetics were taken.

d) People with diabetes having hypertension were included in the study as hypertension is usually comorbid with diabetes.

e) People with chronic medical illness like; cancer, HIV-AIDS, and myocardial infarction etc were excluded from the study.

f) The duration of illness was at least one year.

g) Only those participants were included who never gone through any psychological treatment.

\section{Measures}

\section{Demographic Data Sheet}

A self-developed demographic sheet consists of age, gender, marital status, level of education, job status, family status, residence, type of disease, duration of disease, duration of treatment, comorbidity of any other physical illness, any psychological pressure or tension due to diabetes etc.

\section{Perceived Stress Scale}

Its original version was developed by Cohen, Kamarck and Mermelstein, (1983) consists of 10 items with 5 point Likert type scale, ranging from never to very often. PSS-10 scores are obtained by reversing the scores on the four positive items, e.g. $0=4,1=3.2=2$, etc. and then summing across all 10 items 4, 5, 7, and 8 is the positively stated items. Coefficient alpha reliabilities for the scale have ranged from.84 to .86; test retest reliabilities have ranged from .55 to .85 . The Cronbach's alpha reliability coefficient of.49 for this sample was deemed low. However for current research its Urdu Version was used and the Cronbach's alpha reliability coefficient is .79 which is adequate, for the current diabetic sample (Rauf, 2012).

\section{Procedure}

For data collection permission was taken from "Ethical Research Committee" of Department of Medicine, Jinnah Postgraduate Medical Centre, Karachi, and Department of Diabetes, PNS Shifa Hospital, Karachi. To collect data, the entire diabetic sample of 96 adults with age range 25 to 75 was selected. After getting the permission from the authorities, participants were approached. After establishing rapport they were required to fill in the informed consent form and information regarding demographic variables was 
taken through self-developed demographic sheet and later Perceived Stress Scale was administered. Further for statistical analysis, descriptive statistics and t-test for independent mean were calculated to explore the differences of scores on the variable undertaken through Statistical Packages of Social Sciences (SPSS, 21).

\section{Ethical Consideration}

Initially the synopsis of the research was approved by the Board of Advanced Studies and Research (BASR) University of Karachi, as a partial requirement of M.Phil. Then the permission was taken from the authors of the scales. The permission from Ethical Research Committee for the research at Jinnah Post Graduate Medical Centre was taken and the same permission letter was utilized at Pakistan Navy, Shifa Hospital Karachi. Participant's respect, dignity, right and welfare were ethically and majorly protected in this study. Information was taken according to the consent of the participants and they were assured confidentiality regarding their information and opinions. They were told that they have a right to withdraw from the study during any stage of study. At the end of the study all the authorities of different departments, authors of the scales and participants were acknowledged for their cooperation in the research.

\section{Operational Definition of the Variable}

\section{Perceived Stress}

According to Cohen, Kamarck, and Mermelstein (1983) "perceived stress involves interpretation of the meaning of an event and the interpretation of the adequacy of coping resources". 


\section{Results}

Table: 1

Summary of socio-demographic characteristics of female and male diabetic adults $(\mathrm{N}=48)$

\begin{tabular}{|l|c|c|c|c|c|}
\hline \multicolumn{2}{|c|}{} & \multicolumn{2}{c|}{ Female Adults } & \multicolumn{2}{c|}{ Male Adults } \\
\hline Variables & Category & Frequency & \% & Frequency & \% \\
\hline Education & Primary-Inter & 40 & 83.3 & 37 & 77.1 \\
\hline & Graduate & 4 & 8.3 & 10 & 20.8 \\
\hline & $>$ Graduate & 4 & 8.3 & 1 & 2.1 \\
\hline Marital Status & Unmarried & 7 & 14.6 & 4 & 8.3 \\
\hline & Married & 41 & 85.4 & 44 & 91.7 \\
\hline Job Status & Business & 0 & 0.0 & 8 & 16.7 \\
\hline & Govt. Job & 4 & 8.3 & 16 & 33.3 \\
\hline & Pvt. Job & 6 & 12.5 & 14 & 29.2 \\
\hline & Housewife/retired & 38 & 79.2 & 10 & 20.8 \\
\hline Socioeconomic status & $14-30,000$ & 16 & 33.3 & 18 & 37.5 \\
\hline & $30,000-50,000$ & 23 & 47.9 & 19 & 39.6 \\
\hline & $>50,000$ & 9 & 18.8 & 11 & 22.9 \\
\hline Family Status & Joint & 27 & 56.3 & 21 & 43.8 \\
\hline & Nuclear & 21 & 43.8 & 27 & 56.3 \\
\hline Other Physical Disease & Blood Pressure & 37 & 77.1 & 32 & 66.7 \\
\hline & B.P/eyesight/arthritis & 11 & 22.9 & 16 & 33.3 \\
\hline Tension/ Distress & Yes & 35 & 72.9 & 34 & 70.8 \\
\hline & No & 13 & 27.1 & 14 & 29.2 \\
\hline
\end{tabular}

Table I depicts that female lied between $5^{\text {th }}$ grade to Intermediate level of education with maximum ratio of $83.3 \%$ than male adults. Ratio of being married was high among males $91.7 \%$ than females $85.4 \%$, more female adults lived in joint set up with ratio of $56.4 \%$ and more male adults lived in nuclear family set up 56.4\%, more female adults were with high blood pressure $(77.1 \%)$ than male adults $(66.7 \%)$ and females suffered from more psychological tension and stress of having this disease $72.9 \%$ than male adults $70.8 \%$. 
Table: 2

Summary of percentages of duration of disease among female and male adults with diabetes

\begin{tabular}{|l|c|c|c|c|c|}
\hline \multicolumn{2}{|c|}{ Variables } & \multicolumn{2}{|l|}{ Female Adults } & \multicolumn{2}{l|}{ Male Adults } \\
\hline Duration of Disease & Category & Frequency & \% & Frequency & \% \\
\hline & $1-5$ years & 16 & 33.3 & 13 & 27.1 \\
\hline & 6-10 years & 15 & 31.3 & 16 & 33.3 \\
\hline & $11-15$ years & 7 & 14.6 & 9 & 18.8 \\
\hline & $16-20$ years & 9 & 18.8 & 8 & 16.7 \\
\hline & 21-25 years & 0 & 0.0 & 1 & 2.1 \\
\hline & 26-30 years & 1 & 2.1 & 1 & 2.1 \\
\hline
\end{tabular}

Table shows difference in the ratio of occurrence of duration of diabetes among male and female. As in the current findings high ratio of female population is $33.3 \%$ that is engulfed by diabetes since 1-5 years back than ratio of occurrence of diabetes in males that is $27.1 \%$ between the time period of $1-5$ years. However, male ratio $33.3 \%$ of duration of disease is high that lie between period of 6-10 years than female ratio than falls $31.3 \%$ in the same time period. Further, male persons have more ratio of $18.8 \%$ that falls in the time period of disease between 11-15 years than females.

Table: 3

Summary of percentages of duration of treatment among female and male adults with diabetes

\begin{tabular}{|c|c|c|c|c|c|}
\hline \multicolumn{2}{|c|}{ Variable } & \multicolumn{2}{c|}{ Female Adults } & \multicolumn{2}{c|}{ Male Adults } \\
\hline Duration of Treatment & Category & Frequency & $\%$ & Frequency & $\%$ \\
\hline & $1-5$ years & 18 & 37.5 & 23 & 47.9 \\
\hline & $6-10$ years & 13 & 27.1 & 11 & 22.9 \\
\hline & $11-15$ years & 9 & 18.8 & 6 & 12.5 \\
\hline & $16-20$ years & 7 & 14.6 & 6 & 12.5 \\
\hline & $21-25$ years & 1 & 2.1 & 1 & 2.1 \\
\hline & $26-30$ years & 18 & 37.5 & 1 & 2.1 \\
\hline
\end{tabular}

Above table highlights differences in the ratio of occurrence of duration of treatment of diabetes among male and female persons. As in the current findings male persons seems to have instant treatment for their disease than female with high ratio of $47.9 \%$ for taking treatment that falls between period of 1-5 years than ratio of taking treatment of females persons in females that is $37.5 \%$ between the same time period. However, female ratio $27.1 \%$ of duration of treatment is high that lie between period of 6-10 years than male ratio that is $22.9 \%$ in the same time period. Further, findings indicate that female persons are more negligent for seeking treatment about their disease as the ratio of $37.5 \%$ depicts 
that mostly females fall in taking treatment between 26-30 years for their disease than male persons.

Table: 4

Mean scores of male and female individuals with diabetes and on the variable of perceived stress

\begin{tabular}{|c|c|c|c|c|c|c|}
\hline Groups & $\mathbf{N}$ & $\mathbf{M}$ & SD & df & t & Sig \\
\hline Male & 48 & 19.77 & 6.926 & & & \\
\hline & & & & 96 & -2.056 & .043 \\
\hline Female & 48 & 23.18 & 8.842 & & & \\
\hline
\end{tabular}

Above table highlights that there is a significant gender difference on the variable of Perceived Stress $\left(\mathrm{p}<.05^{* *}\right)$ among male and female persons with diabetes and female score higher $(M=23.18)$ than scores of male diabetic patients $(M=19.77)$.

\section{Discussion}

The aim and major focus of the present study was to find out the difference between male and female adults with diabetes on the variable of perceived stress. The overall findings of this study have shown significant gender difference on the variable of perceived stress (table 4). Findings further revealed that female patients with diabetes have high mean score than male diabetic patients (table 4).

On one hand, the reason of perceived stress is constant struggle for achieving better life style when situation is not favourable or they are unable or find it difficult to manage their lives due to other psycho-social or environmental factors they become the victim of psychological stress and a national study reveals that this constant stress exerts negative impact on their quality of life (Rauf \& Ali, in press). It is also supported by a previous research that external factors like bomber attack, social insecurity and poverty are dangerously influencing Pakistan psychologically (Jamali, Ghulamullah, Qureshi \& Mehboob, 2000). Further, socioeconomic conditions, family system, marital status, duration of disease and treatment, level of education are also stress factors for both male and females diabetic adult. As in current study, 56.3\% females are living in joint family system and $85.4 \%$ are married while ratio of male patients is of $43.7 \%$ and $91 \%$. To manage huge family with this chronic disease becomes difficult for a female when they have to play different roles, fulfilling many demands. Economic condition is an important factor to meet the expenditure of the whole family when it is not adequate to manage the demands of basic needs, this stress causes sleep problems, hypertension, diabetes, heart diseases, and other psychological problems such as suicide, irritability, anxiety, tiredness, low self-esteem (Ahmed \& Noushad, 2013). 
Another contributing factor is the level of education that is related to the awareness and effective management of diabetes and findings of the present study revealed that $83 \%$ female adults having education level of less than Intermediates and 77\% male adults with diabetes fall in this range and this is supported by a previous research where ratio of female for low level of education is high as Agardh, et al. (2011) found that lower level of education is a major burden of diabetes with an estimated ratio of $17.2 \%$ in men and $20.1 \%$ of the burden in women. Unfortunately females are at greater risk by this psychological pressure and constant tension than males (Heraclides, Chandola, Witte, \& Brunner, 2012). However, other psychosocial factors are also evident like education level, being housewives, economic condition of family, support from social circle, and the coping style itself are the contributing significant particles of enhancing stress in females (Sacerdote, Ricceri, Rolandsson, Baldi, Chirlaque, \& Feskens, 2012; Smith et al., 2010; Chida \& Hamer, 2008).

The second reason of stress causing diabetes or making this chronic illness worse is attitude towards this illness as by Selye (1976) stress is how one takes an event more threatening than its actual content. During clinical practice it is observed that fear of having a disease is itself a major stress than its actual occurrence and females are seen to have more emotional coping by ignoring their disease, showing helplessness and a previous findings have highlighted that feelings of anxiety and helplessness are common in most people of Pakistan (Jamal, 2006; Karim, Saeed, Rana, Mubbashar \& Jenkins, 2004 ).

\section{Conclusions}

The findings of the current study have revealed the significant difference on the variable of perceived stress in both gender with diabetes in Karachi-Pakistan. Poor dietary habits, not adherence to anti-diabetic medications and mismanagement are resulted by the psychosocial stresses. This stress is one of the casual factors of creating a lack of physical activity and unhealthy behaviours that also affect satisfaction with life and social and personal well-being of diabetic patients.

\section{Limitations and Recommendations}

Following limitations were drawn from this study and important recommendations were given:

- Further, there is a need of clinical psychologists in different hospitals and private clinics to promote a healthy standard of living and to flourish our society with awareness and psycho education about the impact of psychological problem on physical as well as mental health. 
- Furthermore, treatment and coping strategies should be promoted in different diabetic centers by clinical psychologists to get the people aware to tackle such illness and its stress for better quality of life.

\section{References}

Adriaanse, M. C., Dekker, J. M., Heine, R. J., Snoek, F. J., Beekman, A. J. \& Stehouwer, C. D. (2008). Symptoms of Depression in People with Impaired Glucose Metabolism or Type 2 Diabetes Mellitus: The Hoorn Study. Diabetic Medicine, vol.25:7, pp.843-849.

Agardh, E. E., Sidorchuk, A., Hallqvist, J., Ljung, R., Peterson, S., Moradi, T. \& Allebeck, P. (2011). Burden of Type 2 Diabetes Attributed to Lower Educational Levels in Sweden. Population Health Metrics, 9; 60, http://www.pophealthmetrics.com

Ahmad, S. \& Noushaad S. (2013). Sorts and Sources of Stress in Pakistan; A Comprehensive Outlook. International Journal of Endorsing Health Science Research, vol.1:1, pp.4-8.

Alberti, G. (2002). The Dawn (Diabetes Attitudes, Wishes and Needs) Study. Practical Diabetes International, vol.19:1, pp.22-24.

American Diabetes Association (2007). Diabetes care in the School and Day Care Setting (Position Statement). Diabetes Care, vol.30:1, pp.S66-S73

Anderson, R. M., Funnell, M. M., Arnold, M, S., Barr, P. A., Edwards, G. J. \& Fitzgerald, J. T. (2000). Assessing the Cultural Relevance of an Education Program for Urban African Americans with Diabetes. The Diabetes Educator, vol.26:2, pp.280289.

Barnett, K. N., Ogston, S. A., McMurdo, M. E. T., Morris, A. D. \& Evans, J. M. M. (2010). A 12-Year Follow-Up Study of All Cause and Cardiovascular Mortality among 10532 People Newly Diagnosed with Type 2 Diabetes in Tayside, Scotland. Diabetes Medicines, vol.27:10, pp.1124-1129.

Bener, A., Abdulla, O. A. A., Al-Hamaq \& Dafeeah, E. E. (2011). High Prevalence of Depression, Anxiety and Stress Symptoms among Diabetes Mellitus Patients. The Open Psychiatry Journal, vol.5:5, p.12. 
Cherrington, A., Ayala, G. X., Sleath, B. \& Corbie-Smith, G. (2006). Examining Knowledge, Attitudes, and Beliefs About Depression among Latino Adults with Type 2 Diabetes. The Diabetes Educator, vol.32:4, pp.603-613.

Chida, Y. \& Hamer, M. (2008). An Association of Adverse Psychosocial Factors with Diabetes Mellitus: A Meta-Analytic Review of Longitudinal Cohort Studies. Journal of Diabetologia, vol.51:12, pp.2168-2178.

Chin, M. H., Polonsky, T. S., Thomas, V. D. \& Nerney, M. P. (2000). Developing a Conceptual Framework for Understanding Illness and Attitudes in Older, Urban African Americans with Diabetes. The Diabetes Educator, vol.26:2, pp.439-449.

Coelho, R., Amorim, I. \& Prata, J. (2003). Coping Styles and Quality of Life in Patients with Non-Insulin-Dependent Diabetes Mellitus. Psychosomatics, vol.44, pp.312318.

Cohen, S., Kamarck, T. \& Mermelstein, R. (1983). A Global Measure of Perceived Stress. Journal of Health and Social Behaviour, vol.24:4, pp.385-396.

Collins, M. M., Bradley, C. P., Sullivan, T. \& Perry, I. J. (2009). Self-Care Coping Strategies in People with Diabetes: A Qualitative Exploratory Study. BMC Endocrine Disorders, vol.9:1, pp.6-16.

Cosgrove, M. P., Sargeant, L. A., Caleyachetty, R. \& Griffin, S. J. (2012). Work-Related Stress and Type 2 Diabetes: Systematic Review and Meta-Analysis. Occupational Medicine (Lond), vol.62:3, pp.167-173.

Delahanty, L. M., Grant, R. W., Wittenberg, E., Bosch, J. L., Wexler, D. J. \& Cagliero, E. (2007). Association of Diabetes-Related Emotional Distress with Diabetes Treatment in Primary Care Patients with Type 2 Diabetes. Diabetic Medicine, vol.24:1, pp.48-54.

Drum, D. \& Zierenberg, T. (2005). Type II Diabetes Source Book ( $3^{\text {rd }}$ ed.). USA: McGraw-Hill Companies.

Gazmararian, J. A., Ziemer, D. C. \& Barnes, C. (2009). Perception of Barriers to SelfCare Management among Diabetic Patients. The Diabetes Educator, vol.35:5, pp.778-788.

Goldstein, B. J. \& Muller-Wieland, D. (Eds.), (2003). Text Book of Type 2 Diabetes, http://books.google.com.pk/books?id 
Harris, M. (2007). Psychosocial Aspects of Diabetes with an Emphasis on Depression. Current Diabetes Reports, vol.3:1, pp.49-55.

Heraclides, A. M., Chandola, T., Witte, D. R. \& Brunner, E. J. (2012). Work Stress, Obesity and the Risk of Type 2 Diabetes: Gender-Specific Bidirectional Effect in the Whitehall II study. Obesity (Silver Spring), vol.20:2, pp.428-433.

Husseini, A., Abdul-Rahim, H., Awartani, F., Jervell, J. \& Bjertness, E. (2000). Prevalence of Diabetes Mellitus and Impaired Glucose Tolerance in a Rural Palestinian Population. Eastern Mediterranean Health Journal, vol.6:5-6, pp.1039-45.

International Diabetes Federation. (2006). Diabetes Blue circle Symbol, https://en.wikipedia.org/wiki/Gestational_diabetes\#cite_note-1

International Diabetes Federation. (2010). Types of Diabetes, http://www.idf.org/typesdiabetes.

Jamal, A. (2006). Gender, Citizenship, and the Nation-State in Pakistan: Willful Daughters or Free Citizens? Signs, vol.31:2, pp.283-304.

Jamali, A. R., Ghulamullah, S., Qureshi, I. \& Mehboob, G. (2000). Human Cost of Political Violence. Journal of Pakistan Medical Association, vol.50:1, pp.25-28.

Jiang, L., Beals, J., Nancy, R., Phyvette, W., Roubideaux, Y., Spero, M. \& Manson. (2007). Stress Burden and Diabetes in Two American Indian Reservation Communities. Diabetes Care, vol.31:3, pp.427-429.

Jones, R. A., Utz, S. W., Williams, I. C., Hinton, I., Alexander, G. \& Moore, C., et al. (2008). Family Interactions among African Americans Diagnosed with Type 2 Diabetes. The Diabetes Educator, vol.34:2, pp.318-326.

Karim, S., Saeed, K., Rana, M. H., Mubbashar, M. H. \& Jenkins, R. (2004). Pakistan Mental Health Country Profile. International Review of Psychiatry, vol.16:1-2, 83-92.

Largo-Wigh, E., Peterson, M. \& Chen W. W. (2005). Perceived Problem Solving, Stress, and Health among College Students. American Journal of Health Behaviour, vol.29:4, pp.360-370. 
Lazarus, S. R. \& Folkman, S. (1984). Stress, Appraisal and Coping. (pp.445). Springer Publishing, New York.

Logue, J., Walker, J. J., Colhoun, H. M., Leese, G. P., Lindsay, R. S., McKnight, J. A., et al. (2011). Do Men Develop Type 2 Diabetes at Lower Body Mass Indices than Women? Dia-Betologia, vol.54:12, p.3003.

Luthra, D. (2010). A Link between Stress and Diabetes. Webmed Central Psychiatry, vol.1:10, pp.1-6.

Madonna, M., Roche \& Wang, P. P. (2014). Factors Associated with a Diabetes Diagnosis and Late Diabetes Diagnosis for Males and Females. Journal of Clinical \& Translational Endocrinology, vol.1, pp.77-84, http/dx. doi.org/10.1016/j.jcte. 07.002 .

Malmusi, D., Artazcoz, L., Benach, J. \& Borrell, C. (2012). Perception or Real Illness? How Chronic Conditions Contribute to Gender Inequalities in Self-Rated Health. European Journal of Public Health, vol.22:6, p.781.

Manderson, L. \& Kokanovic, R. (2009). Worried All the Time: Distress and the Circumstances of Everyday Life among Immigrant Australians with Type 2 Diabetes. Chronic Illness, vol.5, pp.21-32.

Penckofer, S., Ferrans, C. E., Velsor-Friedrich, B. \& Savoy, S. (2007). The Psychological Impact of Living with Diabetes Women's Day-to-Day Experiences. The Diabetes Educator, vol.33:4, pp.680-690.

Polzer, R. L. \& Miles, M. S. (2005). Spirituality and Self-Management of Diabetes in African Americans. Journal of Holistic Nursing, vol.23, pp.230-250.

Polzer, R. L. \& Miles, M. S. (2007). Spirituality in African Americans with Diabetes: Self-Management Through a Relationship with God. Quality Health Research, vol.17, pp.176-188.

Pouwer, F., Kupper, N. \& Adriaanse, C. M. (2010). Does Emotional Stress Cause Type 2 Diabetes Mellitus? A Review from the European Depression in Diabetes (EDID) Research Consortium. http://www.discoverymedicine.com/Frans

Public Health Agency of Canada (2011). Diabetes in Canada: Facts and Figures from a Public Health Perspective. Ottawa. 
Rauf, U. (2012). Impact of Psychological Problems on Quality of Life among Diabetic Patients. Unpublished M.Phil Thesis. Institute of Clinical Psychology, University of Karachi-Pakistan.

Rauf, U. \& Ali, U. (2015). Predictive Relationship between Depression and Quality of Life among Patients with Type II Diabetes in Karachi-Pakistan. Journal of Basic and Applied Sciences, vol.11, pp.577-582.

Riaz, S. (2009). Diabetes Mellitus. Scientific Research and Essay, vol.4:5, pp.367-373, www.academicjournals.org/sre/PDF/pdf2009

Sacerdote, C., Ricceri, F., Rolandsson, O., Baldi, I., Chirlaque, M. D. \& Feskens, E., Lower Educational Level is a Predictor of Incident Type 2 Diabetes in European Countries: The EPIC-Inter Act study. International Journal of Epidemiology, vol.41:3, 1162-1173. http://ije.oxfordjournals.org/

Samuel-Hodge, C. D., Headen, S. W., Skelly, A. H., Ingram, A. F., Keyserling, T. C. \& Jackson, E. J., et al. (2000). Influences Day-to-Day Self-Management of Type 2 Diabetes among African American Women: Spirituality, the Multi-Caregiver Role, and other Social Context Factors. Diabetes Care, vol.23, pp.928-933.

Seleye, H. (1976). Stress in Health and Disease. Woburn, MA: Butterworth.

Shera, A. S., Jawad, F. \& Maqsood, A. (2007). Prevalence of Diabetes in Pakistan. Diabetes Research \& Clinical Practice, vol.76:2, pp.219-222.

Smith, T. B., John, W. L., Caroline, S. Fox, H. S., Abrahamowicz, M., Nisha D. Almeida, D. N. \& Loucks, B. E. (2010). Life-Course Socioeconomic Position and Type 2 Diabetes Mellitus. The Framingham Offspring Study.American Journal of Epidemiology, vol.173:4, pp.438-447.

Tuncay, T., Musabak, I., Gok, D. E. \& Kutlu, M. (2008). The Relationship between Anxiety, Coping Strategies and Characteristics of Patients with Diabetes. Health Quality Life Outcomes, vol.6:1, pp.79-89.

Vinicor, F. (2004). Diabetes a to $z$ ( $5^{\text {th }}$ ed.). New Delhi: American Diabetes Association, Inc.

Vroomen-Durning, M. (2009). Type 2 Diabetes: Diabetes Caregivers Need to Take Care of Themselves, http://www.everydayhealth.com/diabetes/type2/caregivi-ng/takecare-of-yourself.aspx. 
Willoughby, D. F., Kee, C. C., Demi, A. \& Parker, V. (2000). Coping and Psychosocial Adjustment of Women with Diabetes. The Diabetes Educator, vol.26:1, pp.105112.

World Health Organization Eastern Mediterranean Region. (2010). http://www.who.int/ diabetes/facts/world_figures/en/index2.html.

World Health Organization. (2010). Diabetes. http://www.who.int/ diabetes/en/

Umara Rauf is Ph.D fellow in the Institute of Clinical Psychology, University of Karachi.

Uzma Ali is an Associate Professor in the Institute of Clinical Psychology, University of Karachi.

Mahjabeen Tariq is M.Phil Scholar in the Institute of Clinical Psychology, University of Karachi-Pakistan 